\title{
THERMAL DISCHARGE FROM MULTI-PORT DIFFUSER INTO SHALLOW WATER RIVERS
}

By

SOBEIH M. M. F.'

KHATTAB A. F. ${ }^{3}$,
EL- ALFY, KASSEM S. ${ }^{2}$,

SAAD M.B ${ }^{4}$, SHAWKY Y.M ${ }^{5}$

1- Associate. Prof., Civil Eng. Dept. , Faculty of Engineering, Minufiya Univ., Egypt.

2- Associate Prof., Irrigation \& Hydraulics Dept., Faculty of Eng., Mansoura Univ., Egypt.

3- Prof., Chan. Maintaince Res. Inst., N.W. Res. Centre, Egypt .

4- Prof., Director of Hydr. Res. Inst. (HRI), N.W.Res.Centre, Egypt

5- Ph. D, Researcher, Hydr. Res. Inst. (HRI), Egypt.

\begin{abstract}
In the following research, the phenomena of the thermal pollution from the thermal power plant out-fall structure (multi-port diffuser) in shallow water rivers was studied. The sets of uni-directional multi-port diffusers were experimentally studied. The different characteristics of the out-fall structure (multi-port diffuser), and the different parameters of the flowing water in the river were considered. The study included a derivation of dimensionless curves for the range of river and out-fall structure parameters typical of the prototype river out-fall installations. Also, a general empirical formula, which can be used in designing of the thermal power plant out-fall structure (multi-port diffuser), discharging hot water into shallow river was developed. The validity of the developed formula was tested against two sets of field measurements of a prototype river diffuser. The two sets of the measurements represent values of the relative thermal concentration at any section downstream the diffuser, $\mathrm{C}_{\mathrm{m}} / \mathrm{C}_{0}$, for a wide range of hydraulic and diffuser parameters. A good agreement between the field data and the experimental data was found. Also, the analysis showed that the best fit of both the measured data and the corresponding results from the developed formula had the same shape and the same trend.
\end{abstract}

Manuscript received from Dr. Sobeih M.M.F.

Accepted on : $26 / 9 / 2001$

Engineering Research Journal Vol 24,No 4, 2001 Minufiya University, Faculty of

Engineering, Shebien El-Kom, Egypt, ISSN 1110-1180 
The submerged multi-port diffusers are generally considered to be the most effective means of creating initial rapid dilution of the thermal discharge into rivers. The discharging of the flow through a large number of ports or nozzles, enable the total area available for entrainment to be increased. The rapid mixing occurs just downstream of the diffuser as the high velocity jets entrain the ambient water. Discharges of effluent from the nozzles form a series of submerged jets within the receiving water. The initial momentum carries the jets into the receiving water for a considerable distance and turbulence causing entrainment, is generated at the interface between the jet and the receiving water. The combined effects of entrainment of the ambient fluid and drag forces exerted on the jets by the ambient flow impart momentum to the jets in the direction of the flow, deflecting the jets downstream. The jets of water are normally hotter or less saline than the ambient water and thus less dense. Thus the effect of buoyancy deflects the jets upward. For the shallow water situation, the water surface limits the upward spread and translation of the jets. As entrainment continues, the density difference diminishes, but the buoyant volume increases keeping the buoyancy flux approximately constant.

\section{REVIEW OF PREVIOUS INVESTIGATIONS}

The relative thermal concentration $\mathrm{C}_{\mathrm{m}} / \mathrm{C}_{0}$ at any section in the ambient river downstream the diffuser outlet is defined as the ratio of the difference between the maximum temperature at that section and the natural ambient river temperature $\left(T_{m}-T_{a}\right)$ to the difference between the temperature at the diffuser outlet and the natural ambient river temperature $\left(T_{e}-T_{a}\right)$.

$$
\mathrm{C}_{\mathrm{m}} / \mathrm{C}_{\mathrm{o}}=\left(\mathrm{T}_{\mathrm{m}}-\mathrm{T}_{\mathrm{a}}\right) /\left(\mathrm{T}_{\mathrm{e}}-\mathrm{T}_{\mathrm{a}}\right)
$$

To obtain a general description of the flow characteristics, it is reasonable to assume that the turbulence within the jet is a function of the jet velocity. The turbulence within the ambient flow can be assumed to be a function of the ambient flow velocity and depth of flow. As illustrated in Figure (1), the independent variables are; ambient (river)/effluent (diffuser) velocity ratio $U / V$; the water depth of the ambient flow $H$; the longitudinal distance downstream the diffuser $\mathrm{x}$; the diameter of the diffuser nozzles $\mathrm{D}$; the number of nozzles $n$; spacing between nozzles $s$; the density difference between the ambient and the effluent $\Delta \rho$, the horizontal angle between the axis of the diffuser and the ambient flow direction $\beta$; the vertical angle of the diffuser nozzles with the horizontal $\theta$; and the height of nozzle outlet from the river bed $h$. Thus, the relationship between the independent parameters and the relative thermal concentration can be as follow:-

$$
\mathrm{C}_{\mathrm{m}} / \mathrm{C}_{\mathrm{o}}=\mathrm{F}(\mathrm{x}, \mathrm{U}, \mathrm{H}, \mathrm{W}, \mathrm{V}, \mathrm{D}, \mathrm{s}, \mathrm{n}, \mathrm{h}, \theta, \beta, \Delta \rho)
$$




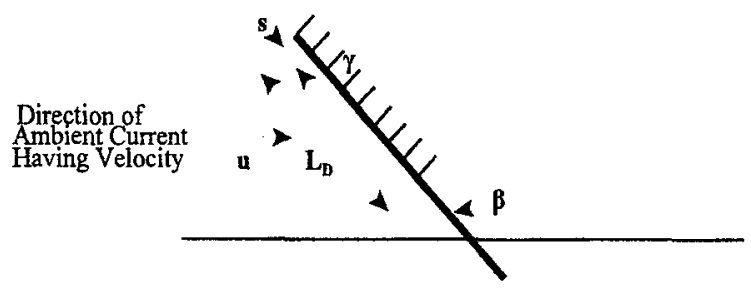

Plan View

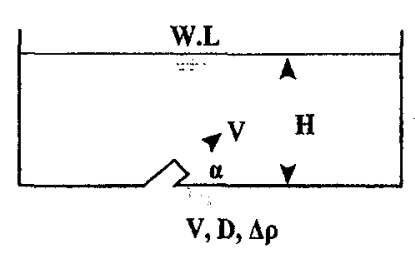

Cross-Section

Figure (1) River and diffuser parameters affecting on relative thermal concentration $\mathrm{C}_{\mathrm{m}} / \mathrm{C}_{0}$

The concentration produced by a circular jet discharging hot water from the bed vertically into shallow open channel was investigated by Rajaratnam \& John [8] (1995). They concluded that the relative thermal concentration is a function of the ratio of the nozzle velocity to the flow velocity (V/U) multiplied by the ratio of the downstream distance to the nozzle diameter (x/D) as follows:-

$$
\frac{C_{o}}{C_{m}}=0.67\left[\frac{V X}{U D}\right]^{0.63}
$$

The above equation is valid only for nozzle discharging hot water vertically and parallel to the flow direction.

In 1998, the effect of $\mathrm{V} / \mathrm{U}$ on $\mathrm{C}_{o} / \mathrm{C}_{\mathrm{m}}$ was studied by Ahmed Moawad [2]. He stated that the value of the thermal concentration $C_{0} / C_{m}$ is inversely proportional to the value of $\mathrm{V} / \mathrm{U}$. This fact was conflicted by Rajaratnam and John $K$. Langat equation as it gives higher values of $C_{o} / C_{m}$ with the increase of $\mathrm{V} / \mathrm{U}$ at the same values of $\mathrm{x} / \mathrm{D}$. So the dimensionless parameter $(\mathrm{Vx} / \mathrm{UD})$ should be divided into two terms, $\mathrm{V} / \mathrm{U}$ and $\mathrm{x} / \mathrm{D}$, and the effect of each term on $\mathrm{C}_{0} / \mathrm{C}_{\mathrm{m}}$ has to be studied individually.

Ahmed Moawad studied the effect of nozzles spacing with respect to its diameter ( $/ \mathrm{D}$ ) on $\mathrm{C}_{\mathrm{o}} / \mathrm{C}_{\mathrm{m}}$ and the effect of the number of nozzles (n) on $\mathrm{C}_{\mathrm{m}} / \mathrm{C}_{0}$. Although his study was built on a few data, he concluded that the increase of $s / D$ resulted to a considerable decreasing of $C_{m} / C_{0}$, and the increase of $n$ leads to a considerable increasing values of $C_{m} / C_{o}$.

In 1972, A formula for the near-field dilution of co-flowing diffuser was deduced by Adams, E.E., et al [1]. 


$$
\frac{C_{o}}{C_{m}}=0.5\left[\frac{U H}{V B_{0}}+\sqrt{\left(\frac{U H}{V B_{0}}\right)^{2}+\frac{2 H \cos \theta \sin \gamma}{B_{0}}}\right]
$$

in which $\mathrm{B}_{0}$ is the equivalent slot width $=\pi \mathrm{D}^{2} / 4 \mathrm{~L}_{\mathrm{D}}$.

The effect of the nozzles spacing with respect to its diameter (s/D) was neglected in Adams equation. He replaced the individual ports by an equivalent slot diffuser having the same discharge and momentum flow. So, the study of the effect of $\mathrm{s} / \mathrm{D}$ on $\mathrm{C}_{\mathrm{m}} / \mathrm{C}_{\mathrm{o}}$ in a large scale of measurements was required. Adams also, neglected the effect of the vertical angle of ports $\theta$, the height of the diffuser from the bed level with respect to the water depth $(\mathrm{h} / \mathrm{H})$, and the horizontal angle of the diffuser line with the flow direction $\beta$. This is means that, the use of Adams equation for predicting the thermal concentration is so limited in practical applications.

In 1985, Jon B. Hinwood [6] carried out his experiments using a small laboratory flume and a multi-port diffuser aligned parallel to the ambient current. From considerations of momentum conservation and mixing, and the results of the flume experiments, an expression for the initial dilution in shallow water was established. The results of the field experiments carried out in an esturaine channel were in agreement with the laboratory results and verified the defined expression. A relationship between the initial dilution and the angle between the diffuser and the current was developed from the field studies as follow:

$$
\frac{C_{o}}{C_{m}}=\frac{1}{30}\left[\frac{U}{H}\right]^{0.5} \frac{Y}{D}\left[\frac{L_{D}}{D}\right]\left[1+\frac{\beta}{22.5}\right]
$$

The use of Hinwood equation in practical application is so limited. He studied the effect of $\beta$ on few measurements. So, the study of the effect of $\beta$ on $C_{m} / C_{0}$ in large scale of measurements is required. Also, Hinwood neglected the effect of the vertical angle of ports $\theta$, its height from the bed level with respect to the water depth $(\mathrm{h} / \mathrm{H})$, and the influence of ports spacing (s) and its number $(\mathrm{n})$.

All the aforementioned dimensionless parameters play an important rule in determining the relative thermal concentration of the river downstream the diffuser as it was proved by the previous equations. The use of these equations as aforementioned for predicting the relative thermal concentration is so limited in practical applications. Each equation neglected one or two parameters, which have great effect on $\mathrm{C}_{\mathrm{m}} / \mathrm{C}_{0}$. Also, their results were built on few data and for special cases of diffusers installation. So, the need for developing general accurate design formula for multi-port diffuser including all parameters affecting on $\mathrm{C}_{\mathrm{m}} / \mathrm{C}_{0}$ was requested. 
The general dimensionless equation which can describe the effect of both the diffuser and the river parameters on the relative thermal concentration - can be written as follows:

$$
\frac{C_{o}}{C_{m}}=f\left[\frac{X}{D}, \frac{V}{U}, n, \frac{S}{D}, \frac{\theta h}{H}, \beta\right]
$$

According to the above function, a number of curves were illustrated to represent the relationship between the thermal concentration $C_{m} / C_{o}$ and the dimensionless distance, $\mathrm{x} / \mathrm{D}$, for different values of $\mathrm{V} / \mathrm{U}, \mathrm{n}, \mathrm{S} / \mathrm{D}, \theta \mathrm{h} / \mathrm{H}$, and $\beta$.

\section{EXPERIMENTAL SET-UP}

A fixed bed flume is required to study the near field performance of a series of uni-directional multi-port diffuser discharges hot water across part of the width of a flowing open channel. A flume was constructed mainly for this purpose in the Hydraulics Research Institute (HRI), National Water Research Center, Ministry of Water Resources and Irrigation as shown in Figure (2). The dimensions of the flume are $15 \mathrm{~m}$ long, $2 \mathrm{~m}$ wide, and $0.4 \mathrm{~m}$ deep. The flume was constructed, from cement-sand mortar, over a $0.5 \mathrm{~m}$ thickness layer of sand, to minimize the heat transfer from hot water to the model bed. The water was pumped to the flume from main basin, which was directly connected by the Nile river by a pipe of 16 inch diameter. The Water was pumped from the basin to the flume by a centrifugal pump with a total capacity of $100 \mathrm{~L} / \mathrm{s}$ through a pipe line of 10 inch diameter. The water was released from the flume outlet to the Nile using under-ground drain, which was connected with the Nile River by pipe of 16 inch diameter. So, the model took and released its water from and to the Nile river, respectively and continuously and this prevent recirculating of hot water into the model.

The series of uni-directional multi-port diffusers with nozzles diameters of $3.2,6.4,9.6,12.7$, and $15.8 \mathrm{~mm}$ were manufactured in HRI workshop. The distance between any two adjacent nozzles centerline was kept constant (twice the port diameter), so that the spacing between nozzles with respect to its diameter $(\mathrm{s} / \mathrm{D})$ could be changed and tested by closing or opening even number of some nozzles. The length of the diffuser $L_{D}$, was defined as the distance between the centers of the outermost nozzles.

An intensive calibration program was made for all the equipments and data acquisition system (thermostats, boiler data acquisition system, electromagnetic currentmeter and electromagnetic flowmeter) and the flume parts . 

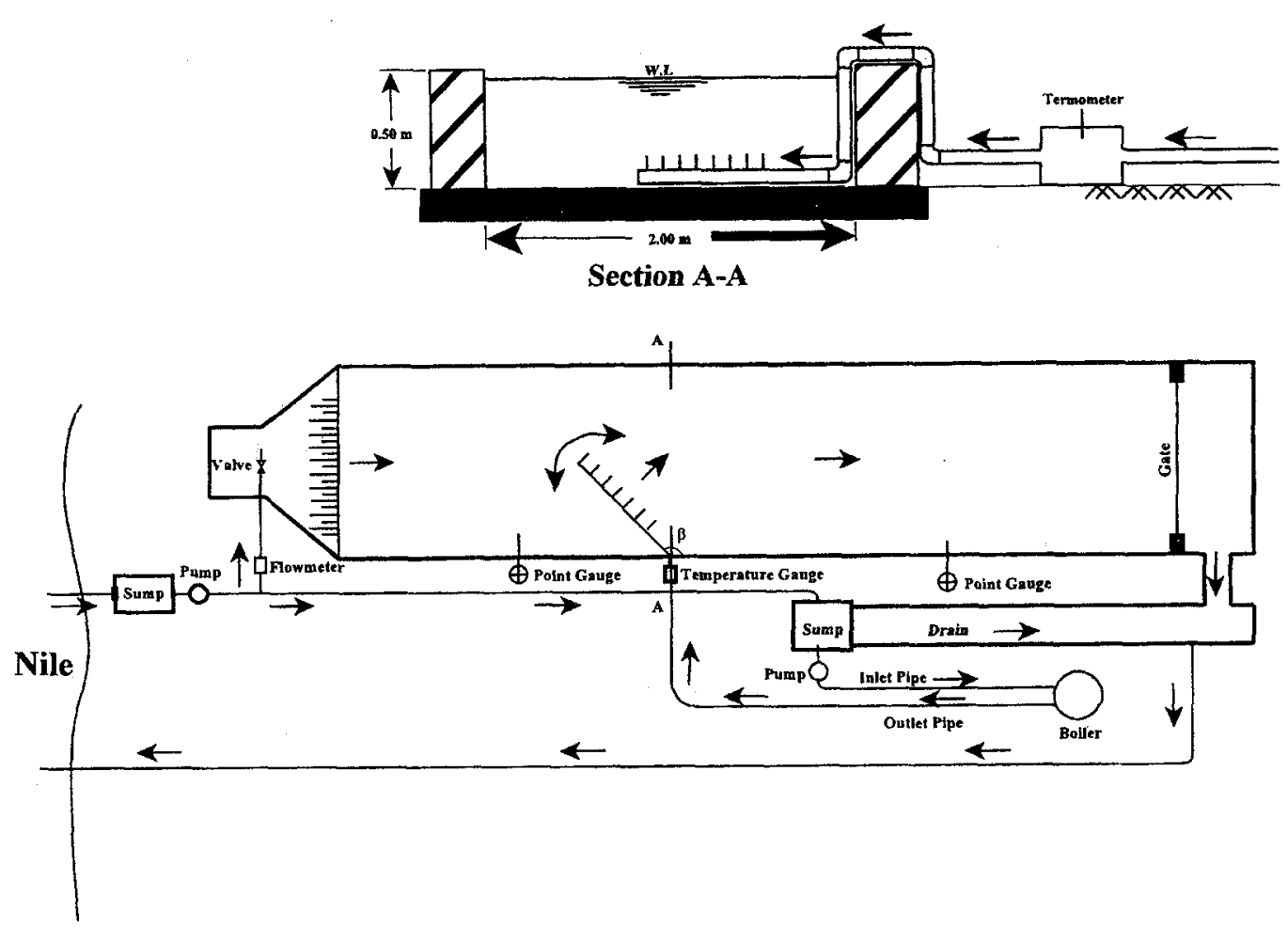

Figure (2) Longitudinal Profile of the Proposed Flume for Multi-Port Diffusers Study,

The heated discharge was delivered from a controlled temperature boiler. It has a constant temperature output with an accuracy of $\pm 0.3 \mathrm{C}^{\circ}$. Each tested diffuser was connected to the out-let pipe and discharged hot water into the model through its nozzles. The hot water flow rate was controlled by valve installed on the outlet pipe of the boiler and measured by electromagnetic flow meter. A double manifold system ensured an equal distribution of discharge flow to each of the discharge nozzles, which were positioned at the appropriate locations $1 \mathrm{~cm}$ off the flume floor

The temperature measurement system consisted of 32 temperature sensing probes and 32 channel scanner capable of scanning the probes in 2 min. One probe was used in the manifold system to monitor discharge temperature, and the remaining probes were used to monitor the receiving water temperature. The thirty two probes were mounted on a woody bridge with $7 \mathrm{~cm}$ distances between each others and cover the whole width of the flume. The bridge was manufactured so that it can move easily in the vertical and horizontal direction above the flume walls. The flow velocity was adjusted to be uniform along the flume by using a number of wood bars with equal distances installed at the model entrance. Each tested diffuser was placed at $7 \mathrm{~m}$ from the flume entrance. This distance was found to be enough for adjusting the flow to be uniform before reaching to the measuring zone. 


\section{EXPERIMENTAL PRODCEDURE}

- The Reynolds number of jets for all the experiments was kept greater than 4000. The density difference ratio $\Delta \rho / \rho$ is a function of temperature difference between ambient and effluent $\Delta T$ and the ambient temperature $T_{a}$. To keep the density difference be constant in all tests, the temperature difference between the boiler and the stream was kept $12^{\circ} \mathrm{C}^{\circ}$, while the temperature of the receiving water was changed from $24-26 \mathrm{C}^{\circ}$ during the time period of measurements.

An expression of the growth of jet rising (jet diameter $d$ ) as a function of U/V, x, D, was deduced by Chan, T.L., [3] 1976. For the cases at which the growth of jets rising was restricted by the water depth $(\mathrm{d} \geq \mathrm{H})$, they will be subject to shallow water conditions over a wide range of $U / V$. As the jet diameter less than the water depth, the water considered shallow and otherwise the water was considered deep. This criteria was applied for each test to insure that the water would be shallow in all tests. Also relative depth of the cross flow H/D was maintained in the range of 10 to 20 to insure that the jets would be in the mixing region. i.e. shallow water condition, Ahmed .M [1].

The experiments were divided into five main categories according to the direction of the diffuser line with the flow direction (angle $\beta$ ). The angles considered were $90^{\circ}, 112.5^{\circ}, 135^{\circ}, 157.5^{\circ}$, and $180^{\circ}$. For each category, 125 experiments were performed over the practical ranges of $\mathrm{x} / \mathrm{D}=10$ to 100 , V/U $=2$ to $6, \mathrm{n}=4$ to $12, \mathrm{~S} / \mathrm{D}=4$ to 12 and $\theta=90^{\circ}$ to $180^{\circ}$ and $\mathrm{h} / \mathrm{H}=0.1$ to 0.3 .

The flume water level and discharge were adjusted to the desired value by a tail gate installed at the end of the flume and electromagnetic flow-meter installed at the inlet-pipe of the flume. The heated water source was adjusted to the desired temperature, and then allowed to flow through the diffuser bypass line. An initial temperature scan was taken to ensure that flume temperature was homogeneous and to enable the background temperature to be established. The diffuser bypass line was closed, while the diffuser feedline opened, and the flow rate adjusted to the desired value. At each test, the temperature of the probes was read after a certain time at which the discharge plume had reached to the far basin wall. Also, the steady-state conditions in the vicinity of the diffuser were established. Temperature readings were carried out at six positions downstream each tested diffuser. These positions were so selected that they cover the range of $x / D$ equals 10 to 100 . At each position, three sections were considered at $0.2,0.5$, and $0.8 \mathrm{H}$. At each section, thirty two probe were scanned three times in six minutes. The max concentration $C_{m}$ at each position was considered the mean of the highest two concentration readings at the three sections at that position 
Four tests were chosen as samples to explain the flow field of the multiple jets in a receiving water body. The concentration field in the deflected jets was measured in the transverse direction $z$, in the longitudinal direction $x$, and in the vertical direction $y$ at different stations along the jet axis. A typical transverse and vertical concentration profiles in the plane in which the maximum concentration occurs were plotted for different sections downstream of the diffuser. Also, the concentration field of the jets was described by plotting concentration contours at a number of sections.

In the first sample of the chosen tests the diffuser was installed perpendicular to the flow direction and discharged horizontally with spacing between nozzles equal to $12 \mathrm{D}$. This test was chosen to indicate the flow field of the individual jets before merging. For stations closer to the nozzles and before the individual jets were merging, peak values were observed. These peaks happened because each jet diffuser without any significant interference from its neighbors. Their diameter increased and its vertical velocity decreased through entrainment caused by the turbulence generated by their relative motion in the $y$-direction. For larger distances downstream the diffuser, the individual peaks have disappeared and the jets became aligned to the direction of the ambient flow and they were merged completely. These distributions were observed also in previous researches, (Ahmed K.M). The second sample of the tests was chosen to indicate the effect of ambienteffluent velocity ratio $\mathrm{V} / \mathrm{U}$ on the flow field of the multiple jets. This test has the same dimensionless parameters of the first test except for $V / U$, as it increased from 4 to 10 . In this case, at large distances downstream the diffuser line, the concentration profiles had two peaks. This can be explained due to the circulation caused by the component of the cross flow velocity $U$ perpendicular to the deflected jet, Wright [10]. This circulation was observed in some tests for shallow water condition in case of high values of $\mathrm{V} / \mathrm{U}$, which agrees with the results observed by, Ahmed K. M [1]. The third sample of tests was chosen to indicate the flow field of multiple jets in case of closer distances among nozzles. This test had the same dimensionless parameters of the first test except for $s / D$, as it decreased from 12 to 4 . In this case, the jets were merged at a distance less than that in the first test and the influence of individual ports was not felt. Generally, it was found that with the increase of $\mathrm{V} / \mathrm{U}$ and $\mathrm{s} / \mathrm{D}$, the jets tended to merge further down stream. In the fourth test the effects of the parameters $\mathrm{V} / \mathrm{U}$ and $\theta \mathrm{h} / \mathrm{H}$ on the flow field of multiple jets in the vertical direction were considered. Also, this test had the same dimensionless parameters of the first test except for $\mathrm{V} / \mathrm{U}$ and $\theta \mathrm{h} / \mathrm{H}$, as they increased from 4 to 10 and from 0.157 to 0.942 , respectively. In the first test, the concentration near the bed reached a high value due to the effect of the bottom of the channel, which restrict the growth of the jet in the vertical direction. The restriction of the growth of the jet in the vertical direction was decreased in the fourth test, due to the increase of $\mathrm{V} / \mathrm{U}$ and $\theta \mathrm{h} / \mathrm{H}$. 


\section{EFFECT OF VERIOUS PARAMETERS ON $\mathrm{C}_{\mathrm{m}} / \mathrm{C}_{\mathrm{o}}$}

The variation of the relative concentration $\mathrm{C}_{\mathrm{m}} / \mathrm{C}_{\mathrm{o}}$ with various parameters was studied for all experiments under the following boundaries $\mathrm{x} / \mathrm{D}=10$ to $100, \mathrm{~V} / \mathrm{U}=2$ to $6, \mathrm{n}=4$ to $12, \mathrm{~s} / \mathrm{D}=4$ to $12, \theta=1.57(90)^{\circ}$ to $3.14(180)^{\circ}$, and $\mathrm{h} / \mathrm{H}=0.1$ to 0.3 . Figures ( 3 to 7 ) show some typical results on the variation of $\mathrm{C}_{\mathrm{m}} / \mathrm{C}_{\mathrm{o}}$ with various dimensionless parameters. These figures show the high and low boundaries of the data envelope for all experiments.

\section{1- EFFECT OF $x / D$ ON $C_{m} / C_{o}$}

From Figure (3), it was clear that in the first experiment the value of $\mathrm{C}_{\mathrm{m}} / \mathrm{C}_{\mathrm{o}}$ was decreased $55 \%$ due the increase of the value of $\mathrm{x} / \mathrm{D}$ from 10 to 100 , while it decreased $4 \%$ in the second experiment due to the same change of $x / D$ values. This means that $C_{m} / C_{0}$ was inversely proportional with $x / D$. This is refer to, the discharge of effluent from the ports of the diffuser which forms a series of submerged jets within the receiving water. The initial momentum carries the jets into the receiving waters for a considerable distance and turbulence causing entrainment, was generated at the interface between the jets and the receiving waters and consequently a rapid dilution of hot water was then created. With the increase of $x / D$, the combined effect of entrainment of the ambient fluid and drag forces exerted on the jets by the ambient flow impart momentum to the jets in the direction of the flow, deflecting the jets downstream. Although the turbulence presents in the ambient flow has less intense than that generated by the jets, the rate of entrainment of the deflected jets may increase and consequently another dilution was created or in other meaning a low concentration was formed.

\section{2- EFFECT OF V/U ON $C_{m} / C_{o}$}

In the first group of experiments shown in Figure (4-a), the concentration values decreased about $20 \%$ at $\mathrm{x} / \mathrm{D}=10$ and $9 \%$ at $\mathrm{x} / \mathrm{D}=100$ due to the change of $\mathrm{V} / \mathrm{U}$ value from 6 to 2 . In the second group shown in Figure (4-b), the decrease of concentration values was found to be equal $8 \%$ at $\mathrm{x} / \mathrm{D}=10$ and $2 \%$ at $\mathrm{x} / \mathrm{D}=100$ due to the same changes of $\mathrm{V} / \mathrm{U}$ value. It was clear from the results that the drop of concentration values is more affected by the change of $V / U$ values in the mixing zone (low values of $x / D$ ) than the far zone (high values of $x / D$ ). This indicated the importance of the dimensionless parameter $\mathrm{V} / \mathrm{U}$, especially in the mixing zone. In general, it could be concluded that the effluent-ambient velocity ratio $\mathrm{V} / \mathrm{U}$ had a great effect on the relative thermal concentration $C_{m} / C_{0}$. As $V / U$ increases $C_{m} / C_{0}$ tends to increase. In the low values of $\mathrm{V} / \mathrm{U}$, the ambient velocity deflects the jets into the downstream direction and thus limit the spread of the jets at aiven distance downstream of the diffuser. In the later stages of the motion, the velocity of the jets, $V$, relative to the ambient flow velocity, $U$, diminishes, 


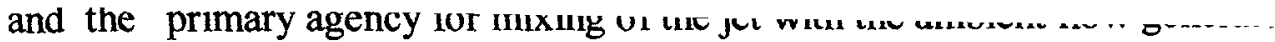
the turbulence into the ambient flow.

\section{3- EFFECT OF $n$ AND s/D ON $C_{m} / C_{0}$}

Two of the important dimensionless parameters which affect on the relative concentration $\mathrm{C}_{m} / \mathrm{C}_{0}$ were the ratio of the spacing between nozzles to the nozzle diameter $(\mathrm{s} / \mathrm{D})$ and the number of nozzles $(\mathrm{n})$. The effect of both $\mathrm{n}$ and $\mathrm{s} / \mathrm{D}$ on $\mathrm{C}_{\mathrm{m}} / \mathrm{C}_{0}$ were studied by plotting $\mathrm{C}_{\mathrm{m}} / \mathrm{C}_{\mathrm{o}}$ against $\mathrm{x} / \mathrm{D}$ at different values of $s / D$ and $n$. The values of $s / D$ were $4,6,8,10$, and 12 , while values of n were $4,6,8,10$, and 12 .

For the first presented group of the experiments shown in Figure (5-a), the values of $\mathrm{C}_{\mathrm{m}} / \mathrm{C}_{0}$ decreased $55 \%$ at $\mathrm{x} / \mathrm{D}=10$ and $15 \%$ at $\mathrm{x} / \mathrm{D}=100$ due to the increase of $\mathrm{s} / \mathrm{D}$ value from 4 to 12 and the decrease of $\mathrm{n}$ value from 12 to 4. For the second group, Figure $(5-b)$, this drop of $C_{m} / C_{0}$ value was found to be $8 \%$ at $x / D=10$ and $2 \%$ at $x / D=100$ due to the same change of $s / D$ and $n$ values. The results indicated that there was generally a decrease in thermal concentration values due to the increase of the value of $s / D$. This could be attributed as the distance between the ports was relatively small, the jets tended to entrain each other closer to the diffuser, and the ambient diluting water was less entrained into the core of the merged jets and hence more concentration occurred. In the case of wider spacing, there was sufficient space between the ports and the merging of the jets was delayed. This allowed the individual jets to be distinct, which resulted in less concentration. The results indicated also that there was generally an increase in thermal concentration values due to the increase of $n$ value. This was due to the interference of the merging plumes on the entertainment mechanisms. The decrease of the available surface area upon merging leads to a decrease of the entrainment for each individual jet.

\section{4- EFFECT OF THE $\theta \mathrm{h} / \mathrm{H}$ ON $\mathrm{C}_{\mathrm{m}} / \mathrm{C}_{0}$}

The variation of the relative concentration $\left(C_{m} / C_{o}\right)$ with the vertical angle between ports and the horizontal $(\theta)$ multiplied by the ratio of the ports height from the river bed to the water depth $(\mathrm{h} / \mathrm{H})$ was studied for different values of $\theta$ and $\mathrm{h} / \mathrm{H}$. The values of $\theta \mathrm{h} / \mathrm{H}$ were equal to $0.157\left(\theta=1.57\left(90^{\circ}\right)\right.$, $\mathrm{h} / \mathrm{H}=0.1) ; 0.294\left(\theta=1.96\left(112.5^{\circ}\right), \mathrm{h} / \mathrm{H}=0.15\right): 0.472\left(\theta=2.36\left(135^{\circ}\right)\right.$, $\mathrm{h} / \mathrm{H}=0.2) ; 0.688\left(\theta=2.75\left(157.5^{\circ}\right), \mathrm{h} / \mathrm{H}=0.25\right)$; and $0.942\left(\theta=3.14\left(180^{\circ}\right)\right.$, $\mathrm{h} / \mathrm{H}=0.3)$. These ranges were found to be covering the practical ranges of $\theta$ and $\mathrm{h} / \mathrm{H}$ in the prototype.

In the first group of experiments, Figure (6-a), the concentration value decreased $23 \%$ at $\mathrm{x} / \mathrm{D}=10$ and $11 \%$ at $\mathrm{x} / \mathrm{D}=100$ due to the decrease of $\theta \mathrm{h} / \mathrm{H}$ value from 0.942 to 0.314 . In the second group, Figure $(6-b)$, the decrease of $\mathrm{C}_{\mathrm{m}} / \mathrm{C}_{0}$ values equal $7 \%$ at $\mathrm{x} / \mathrm{D}=10$ and $1 \% \mathrm{x} / \mathrm{D}=100$ due to the same change of $\theta \mathrm{h} / \mathrm{H}$ value. The increase of $\theta \mathrm{h} / \mathrm{H}$ leads to a weakly deflected plume 
regime with surface interaction and upstream spreading, while the decrease of $\theta \mathrm{h} / \mathrm{H}$ leads to an intermediate regime with significant blocking and stagnant

- wedge formation. With more decreasing of $\theta \mathrm{h} / \mathrm{H}$ value, a strongly deflected regime in which the plume gradually raises to the free surface, which resulted in less concentration.

\section{5- EFFECT OF $\beta$ ON $C_{m} / C_{0}$}

Figure (7) shows the variation of $\mathrm{C}_{m} / \mathrm{C}_{0}$ versus $\mathrm{x} / \mathrm{D}$ for different values of $\beta$. In the first group of the experiments, Figure (7-a), the concentration value decreased $23 \%$ at $\mathrm{x} / \mathrm{D}=10$ and $13 \%$ at $\mathrm{x} / \mathrm{D}=100$ due to the decrease of $\beta$ value from 3.14 to 1.57 . In the second group, Figure $(7-b)$, the decrease of $\mathrm{C}_{\mathrm{m}} / \mathrm{C}_{0}$ values was equal $7 \%$ at $\mathrm{x} / \mathrm{d}=10$ and $2 \%$ at $\mathrm{x} / \mathrm{D}=100$ due to the same change of $\beta$. It could be concluded that the relative thermal concentration $\mathrm{C}_{\mathrm{m}} / \mathrm{C}_{\mathrm{o}}$ was directly proportional to the value of the horizontal angle of the diffuser $\beta$. This relationship was proved in other previous researches (Jirks, Harleman [5] 1973 and Jon B. Hinwood [6] 1985. When the angle between the diffuser and the flow direction be small as much as possible, the possible volume of the receiving water was increased, while at the increasing of $\beta$, this volume of water was decreased, which affects on the mixing process and consequently a high concentration was formed.

\section{DEVELOPMENT OF THE GENERAL EMPIRICAL FORMULA}

The existing laboratory data presented in this study was analyzed to obtain a general empirical formula which could be used for predicting the relative thermal concentration of the pollutant downstream the out-fall structure. Based on regression analysis of all observed results, the relation between relative thermal concentration and the above dimensionless terms was developed and the general formula which represents the line of best fit was deduced as follows:-

$$
\frac{C_{m}}{C_{0}}=0.27\left[\frac{x}{D}\right]^{-0.55}\left[\frac{V}{U}\right]^{0.60}(n)^{0.48}\left[\frac{s}{D}\right]^{-0.51}\left[\frac{\theta h}{H}\right]^{0.3}(\beta)^{0.90}
$$

To obtain the percentage difference between the measured and predicted values of $\mathrm{C}_{\mathrm{m}} / \mathrm{C}_{0}$, they were plotted against each others as shown in Figure (8) and the line of equality was drawn. The correlation factor between them was above $0.9,\left(R^{2}>0.9\right)$.

\section{A COMPARITIVE STUDY WITH PARR (1979) AND HINWOOD (1985)}

The validity of the developed formula was tested against two sets of laboratory and prototype data ( $\{$ Parr and Sayre [7] 1979\} and \{Jon B. 
Hinwood [6] 1985\}). The data represents tne values or $\cup_{m^{\prime}} \cup_{0}$ tve a was range of flow and diffuser parameters.

With respect to Parr and Sayre data, a series of field measurements were performed at the Quad Cities multi-port diffuser system. At the tested zone, the river width was about $671 \mathrm{~m}$ and the average depth in the main channel was about $7.6 \mathrm{~m}$. The diffuser-pipe system actually consists of two manifold pipes each $4.9 \mathrm{~m}$ diameter. This pipe was equipped with five small ports of $(55 \mathrm{~cm})$ diameter and twenty large ports of $(82 \mathrm{~cm})$ diameter. All of the ports were directed in the downstream direction at a $20^{\circ}$ angle with horizontal. About $90 \%$ of the total effluent discharge passed through the large ports in a section of the river of $120 \mathrm{~m}$ wide. The rest of the hot water was discharged through the five small ports. It was assumed that all of the effluent passes through the portion of the diffuser pipe equipped with the large ports (Parr 1981). Temperature were measured upstream and downstream from the discharge section of the river in order to determine the thermal concentration at a cross section $152 \mathrm{~m}$ downstream the diffuser.

In 1981, David Parr [7] developed a mathematical model to predict the dilution, induced by submerged multi-port diffuser discharges in a rectangular channel. The model was analyzed and the results were presented in the form of dimensionless graphs. The dimensionless graphs were based on a mathematical model for an ideal rectangular channel. Since the river is irregular in cross section, the hydraulic parameters of the equivalent rectangular channel (width, depth, velocity and discharge) must be taken into consideration in order to apply the equation to prototype diffuser installation. An equivalent rectangular channel characteristics was defined by David Parr [7] 1981. By assuming that the degree of lateral confinement was due to the availability of ambient mixing water rather than to the actual location of the boundaries, an equivalent rectangular could be determined for a natural river. The depth, $H_{e}$, ambient velocity, $U_{e}$, discharge, $Q_{e}$, and width of the equivalent channel, $W_{e}$, are determined by David Parr [7] 1981. In 1985, Jon B. Hinwood [6] carried out some experiments on the near field dilution using a small laboratory model diffuser and a small laboratory flume.

The developed formula was applied on the multi-port diffuser system at the Quad Cities, and the results were compared by that resulted from both David Parr [7] and Jon B. Hinwood [6] studies as shown in Figure (9).

Figure (9) shows the comparison among the dilution, $\left(C_{d} / C_{m}\right)$, predicted at the estuary by using the developed formula in this study and the data presented by Hinwood and David Parr. It is clear from the figure that, the best fit for the measured dilution takes the same shape and the same trend as that obtained by developed formula. These results indicated the validity of the developed formula and its importance as a good estimation of the thermal concentration into receiving water body. 
Based on Jon B. Hinwood results, a one-fifth scale model outfall was constructed and tested in an estuarine channel near the mouth of port Phillip Bay, (Australia). The model diffuser was $12.2 \mathrm{~m}$ long and was constructed from four lengths of $0.2 \mathrm{~m}$ internal diameter steel pipe bolted together by flanges. It contained 32 ports, each $19 \mathrm{~mm}$ in diameter. The outfall was installed with the diffuser at a distance of $10 \mathrm{~m}$ upstream a bridge crossing the estuary. Seven tests were carried out with the diffuser parallel to the flow, five with the diffuser at an oblique angle, and five with the diffuser perpendicular to the flow. The discharge, $\mathrm{Q}$, was varied from $6-19 \mathrm{~L} / \mathrm{s}$, the salinity of the effluent was varied from $0-35 \mathrm{ppt}$, the ambient current ranged from $0-0.6 \mathrm{~m} / \mathrm{s}$, and the depth ranged from 1.5 to $1.75 \mathrm{~m}$. The developed formula in this study and the two formulae developed by Adams, E., et al [1] 1972 and Jon B. Hinwood [6] were applied on that one-fifth scale model outfall. Figure(12) shows the comparison of the dilution, $\left(\mathrm{C}_{0} / \mathrm{C}_{\mathrm{m}}\right)$, predicted by the developed formula and the previous formulae of Adams and Hinwood. It is clear from the figure that, the best fit for the measured dilution takes the same shape and the same trend as that obtained by the developed formula and the other formulae. The correlation factor between the measured and the predicted values of $\mathrm{C}_{\mathrm{o}} / \mathrm{C}_{\mathrm{m}}$ was found to be equal to $0.87,\left(\mathrm{R}^{2}=0.87\right)$. These results indicated the validity of the developed formula and its importance as a good estimation of the thermal concentration into the receiving water body.

\section{CONCLUSIONS}

The thermal concentration was found to be affected by the effluent (diffuser)-ambient (river) velocity ratio $V / U$, the number of diffuser ports $\mathbf{n}$, the spacing between ports with respect to its diameter $s / D$, the vertical angle of ports with the horizontal $\theta$ multiplied by the relative height $h / H$, and the horizontal angle between the diffuser line and the flow direction $(\beta)$. From the analysis of the results, it can be concluded that the relative thermal concentration $C_{n} / C_{0}$ increases with the increase of $V / U, n, \theta h / H$ and $\beta$, while decreases with the increase of $\mathrm{s} / \mathrm{D}$. The maximum value of $\mathrm{C}_{\mathrm{m}} / \mathrm{C}_{\mathrm{o}}$ in this study was obtained at the case of aiffuser aligned paralleled to the flow direction and when $\mathrm{V} / \mathrm{U}=6, \mathrm{n}=12, \mathrm{~s} / \mathrm{D}=4$ and $\theta \mathrm{h} / \mathrm{H}=0.942$. The minimum value of $\mathrm{C}_{\mathrm{m}} / \mathrm{C}_{\mathrm{o}}$ in this study was obtained at the case of diffuser aligned perpendicular to the flow direction and when $\mathrm{V} / \mathrm{U}=2, \mathrm{n}=4, \mathrm{~s} / \mathrm{D}=12$ and $\theta \mathrm{h} / \mathrm{H}=0.157$. Based on regression analysis and on all the observations, the relation between the relative thermal concentration $C_{m} / C_{0}$ and the above dimensionless parameters was developed and a general formula which represent the lines of best fit was deduced . The validity of the developed formula was tested against two sets of filed and laboratory measurements. It was found that, the best fit for the measured data takes the same shape and the same trend as that obtained by the developed formula. These results indicated the validity of the developed formula and its importance as a good estimation of the thermal concentration into shallow water river. 
1- Adams, E.E., " Submerged multi-port diffuser and the horizontal users in shallow water with current" thesis presented to the Massachusetts Institute of Technology, at Cambridge, Mass, in partial fulfillment of the requirements for the degree of Master of Science, 1972.

2- Ahmed K. M., and Rajaratnam, N., "Dilution of multiple non-buoyant circular jets in cross flows" J.Envir. Eng., ASCE, Vol. 124, No. 1, January 1998.

3- Chan, T.L., Lin, J.T., and Kennedy, J.F., "Entrainment and drag forces of deflected jets" Journal of the Hydraulics Division, ASCE, Vol. 102, No. HY5, pp. 615-635, 1976.

4- Davis L. R., Shirazi M. A., and Siegel D.L., "Measurement of buoyant jet entrainment from single and multiple sources" J. of Heat Transfer, Vol. 100, PP. $442-447,1978$.

5- Jirka, G. H., and Harleman, D. R.F., "The mechanics of submerged multiport diffusers for buoyant discharges in shallow water" Technical Report 169, Ralph M. Parsons Laboratory for Water Resources and Hydrodynamics, Massachusetts Institute of Technology, Cambridge, Mass., 1973.

6- Jon B.H., and Ian G.W., " Initial dilution for outfall parallel to current" J.Hydr. Eng., ASCE, Vol. 111, No. 5, May 1985.

7- Parr, A.D., and Melville, J.G., "Near field performance of river diffusers" Journal of Environmental Engineering, ASCE, Vol. 107, No. EE5, pp. 995 -1008 , October 1981.

8- Rajaratnam, N., and Langat, J. K.," Mixing region of circular turbulent wall jets in cross flows" Journal of Hydraulic Engineering, ASCE, Vol. 121, No. 10, pp. $694-698$, October 1995.

9- Shawky, Yasser, "Near field performance of river multi-port diffuser" A Thesis submitted for the award of Ph.D. in Civil Eng., Faculty of Eng., Minufiya university, 2001.

10-Wright, S. J., "Effects of ambient cross-flows and density stratification on the characteristic behavior of round turbulent buoyant jets." 1977.

\section{NOTATIONS}

The following symbols were used in this paper:

$B_{0} \quad$ equivalent slot width

$C_{0} \quad$ Thermal concentration at the diffuser outlets $=T_{c}-T_{a}$

$\mathrm{C}_{\mathrm{m}}$ maximum thermal concentration at any section downstream the diffuser $=T_{m}-T_{a}$

$\mathrm{C}_{\mathrm{m}} / \mathrm{C}_{0}$ relative thermal concentration at any section downstream the diffuser $=\mathrm{T}_{\mathrm{m}}-\mathrm{T}_{\mathrm{a}} / \mathrm{T}_{\mathrm{e}}-\mathrm{T}_{\mathrm{a}}$

$\mathrm{C}_{\sigma} / \mathrm{C}_{m}$ dilution of thermal concentration at any section downstream the diffuser $=T_{e}-T_{a} / T_{m}-T_{a}$

D nozzle diameter 


\section{d jet diameter \\ $\mathrm{H}$ ambient water depth}

- $\mathrm{H}_{\mathrm{e}} \quad$ upstream ambient depth in rectangular channel

$\mathrm{H}(\mathrm{y})$ local river depth

h elevation of nozzle outlet above the bed river

$L_{D} \quad$ length of diffuser

n number of diffuser ports

$\mathrm{Q}_{\mathrm{a}} \quad$ ambient river discharge

$\mathrm{Q}_{\mathrm{e}} \quad$ effluent discharge

Qeq discharge of equivalent rectangular channel

$q$ local depth averaged river discharge

q- average unit river

s spacing between diffuser nozzles

$\mathrm{T}_{\mathrm{a}} \quad$ local ambient temperature without thermal effluent

$\mathrm{T}_{\mathrm{e}} \quad$ effluent temperature

$T_{m} \quad$ ambient temperature at any section with thermal effluent

$\mathrm{U}$ ambient river velocity

$u_{e} \quad$ velocity of equivalent rectangular channel

$\mathrm{u}_{\mathrm{y}} \quad$ average unaffected ambient rectangular channel

$V$ effluent velocity.

W ambient river width

$\mathrm{W}_{\mathrm{e}} \quad$ width of equivalent rectangular channel

$\mathrm{x}$ perpendicular distance to the diffuser line in the downstream direction

$\beta$ diffuser alignment relative to cross-flow

$\gamma \quad$ nozzle angle relative to diffuser axis

$\Delta p \quad$ density difference

$\beta \quad$ horizontal angle between the diffuser line and the flow direction

$\theta \quad$ vertical angle between diffuser nozzles 


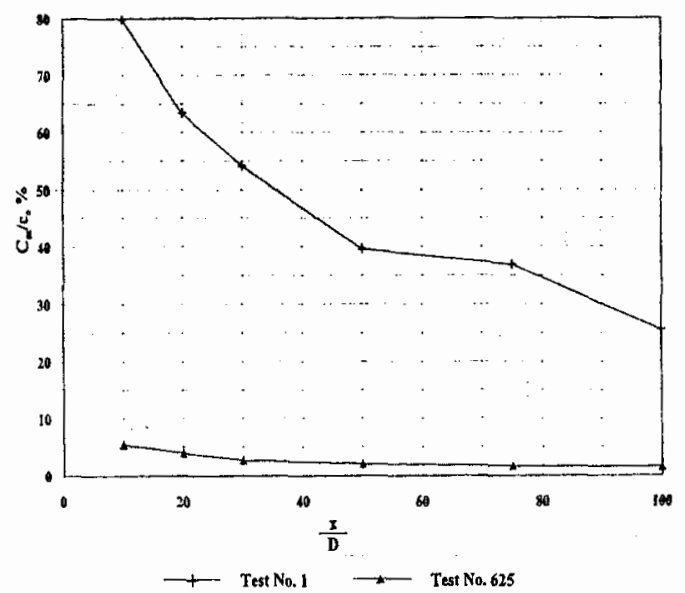

Figure (3) Variation of $C_{m} / C_{0}$ with $x / D$

cases of experiments represent high and boundary of data envelope

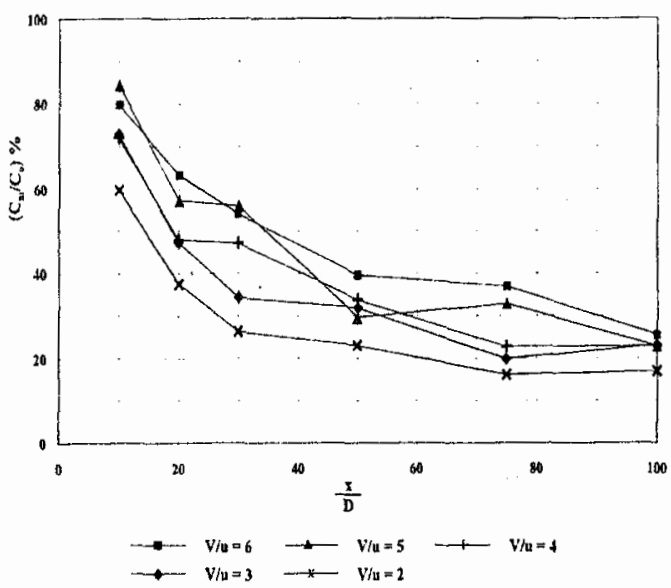

(a)

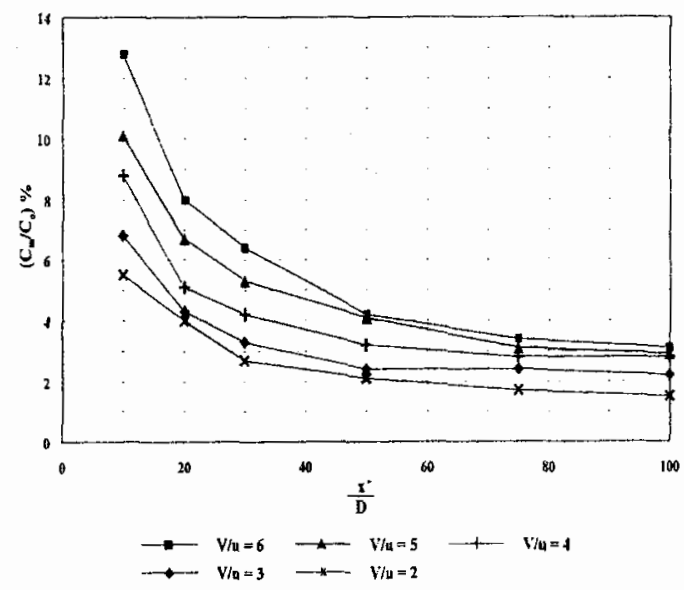

(b)

Figure (4) Variation of $C_{m} / C_{0}$ with $x / D$ Under Different Values of V/U

(a) cases of experiments represent the high boundary of data envelope

(b) cases of experiments represent the low boundary of data envelope

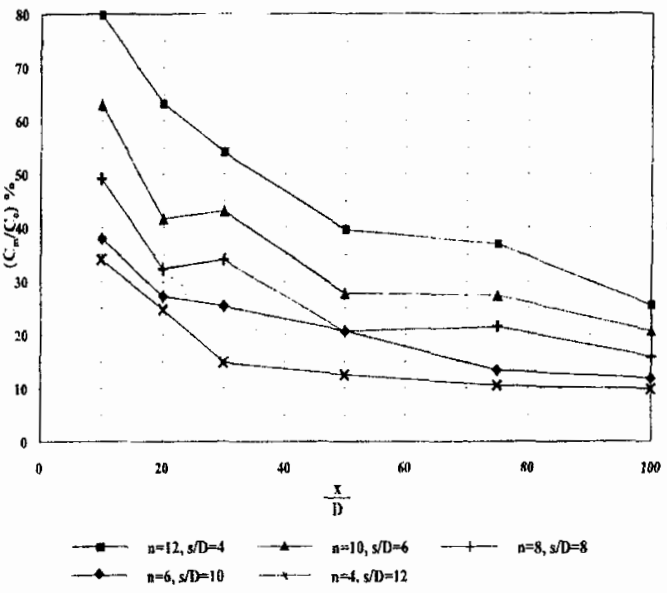

(a)

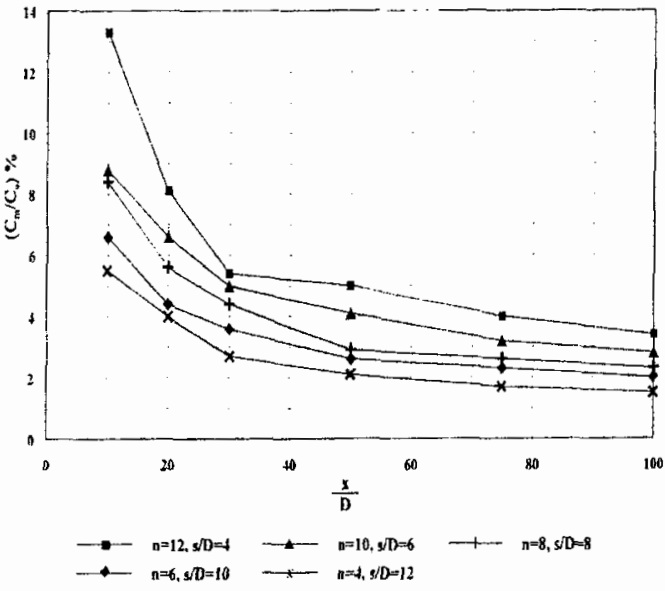

(b)

Figure (5) Variation of $C_{m} / C_{0}$ with $x / D$ Under Different Values of $s / D$ and $n$

(a) cases of experiments represent the high boundary of data envelope

(b) cases of experiments represent the low boundary of data envelope 


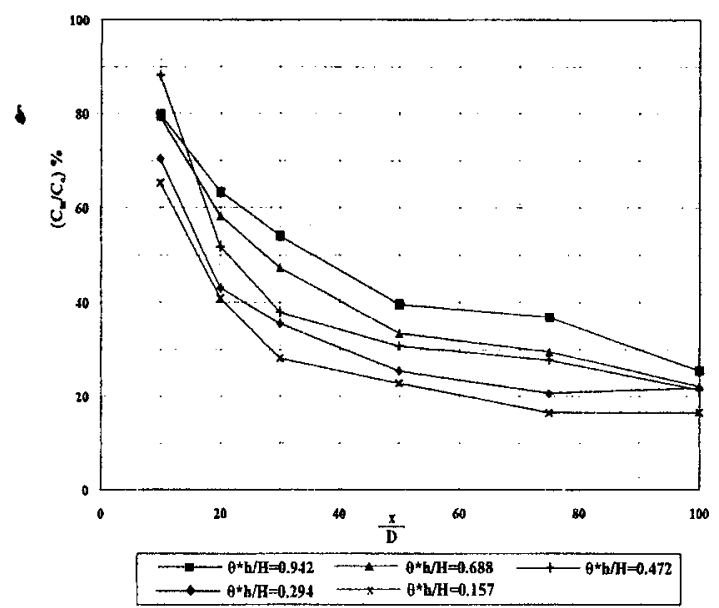

(a)

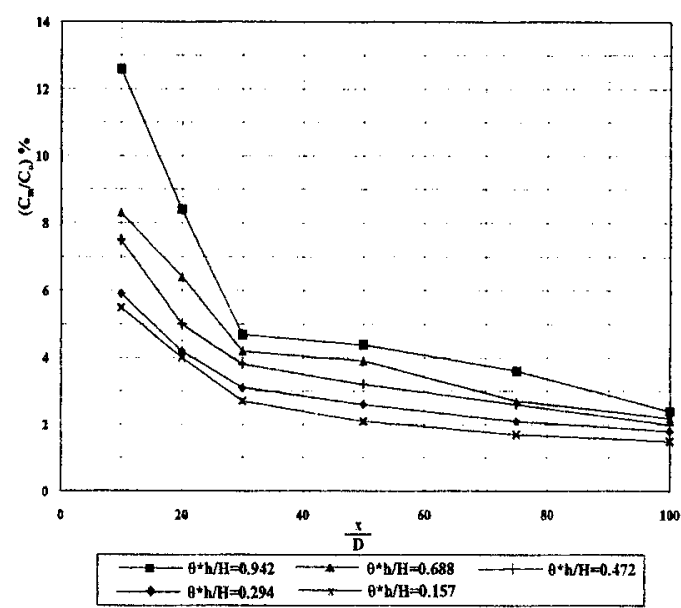

(b)

Figure (6) Variation of $C_{m} / C_{0}$ with $x / D$ Under Different Values of $\theta h / H$

(a) cases of experiments represent the high boundary of data envelope

(b) cases of experiments represent the low boundary of data envelope

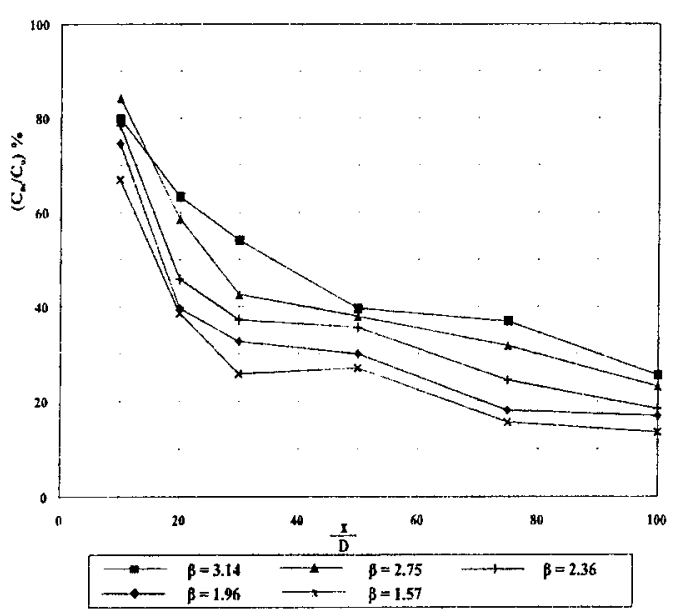

(a)

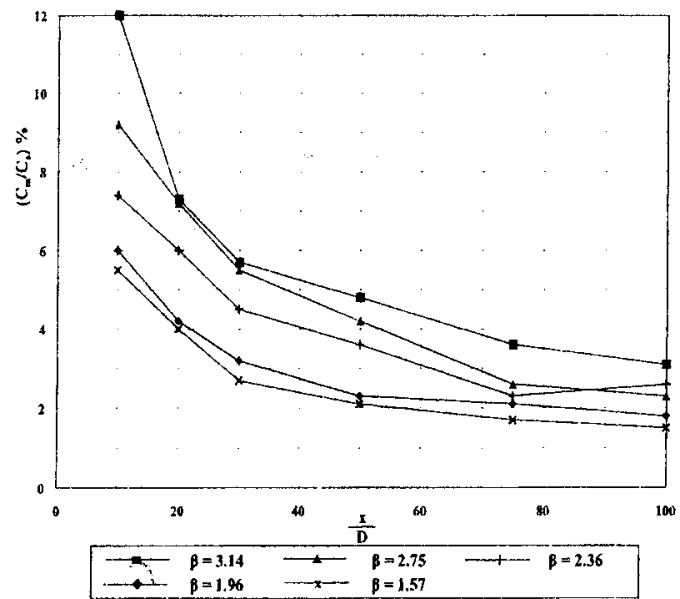

(b)

Figure (7) Variation of $C_{m} / C_{0}$ with $x / D$ Under Different Values of $\beta$ (a) cases of experiments represent the high boundary of data envelope (b) cases of experiments represent the low boundary of data envelope 


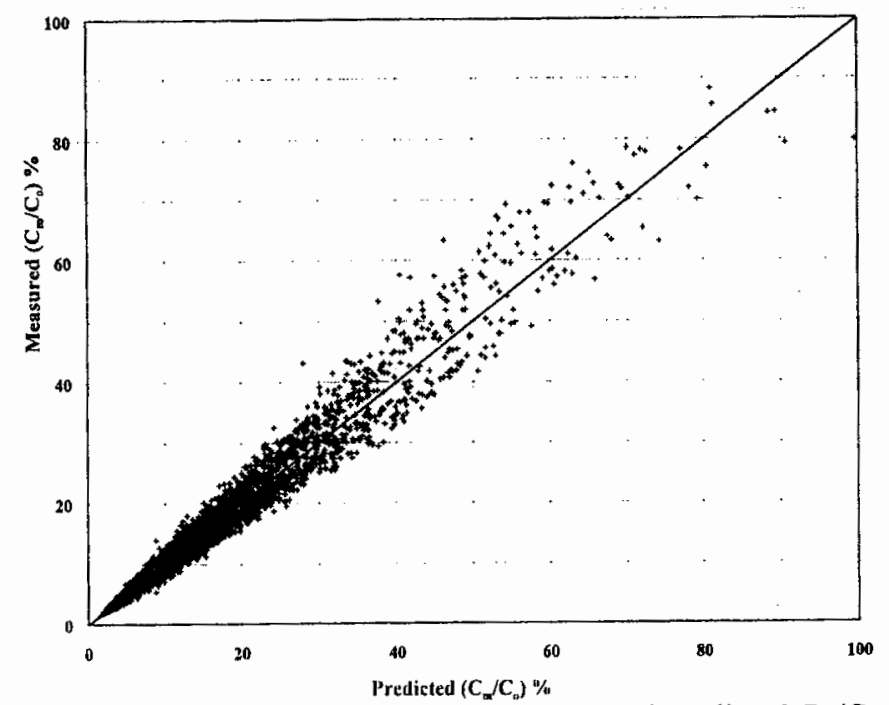

Figure (8) Comparison Between Measured and predicted $\mathrm{C}_{\mathrm{m} n} / \mathrm{C}_{\mathrm{o}}$

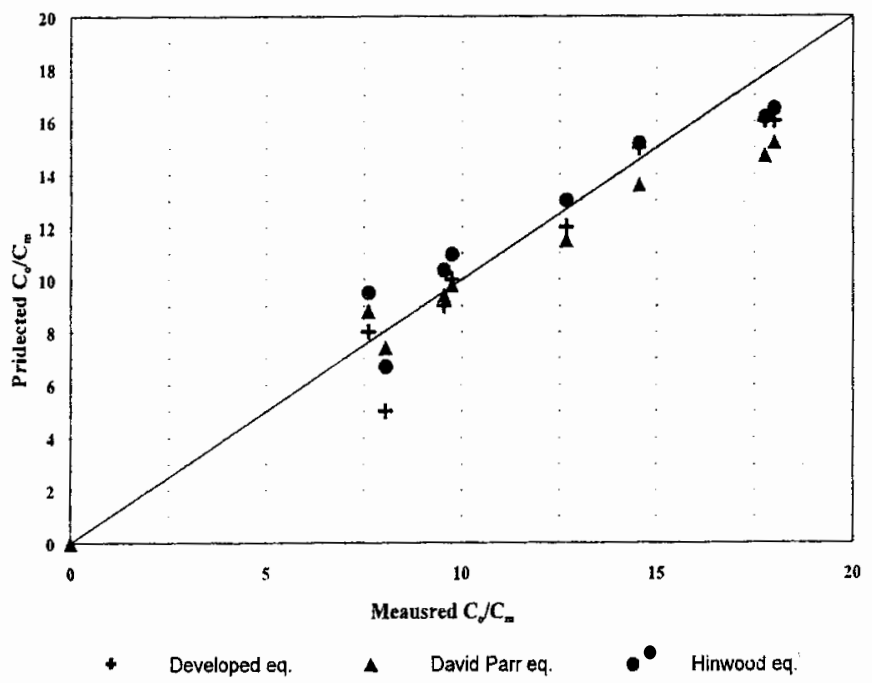

Figure (9) Comparison of Measured and Predicted $C_{o} / C_{m}$ for Quad Cities Multi-port Diffuser System

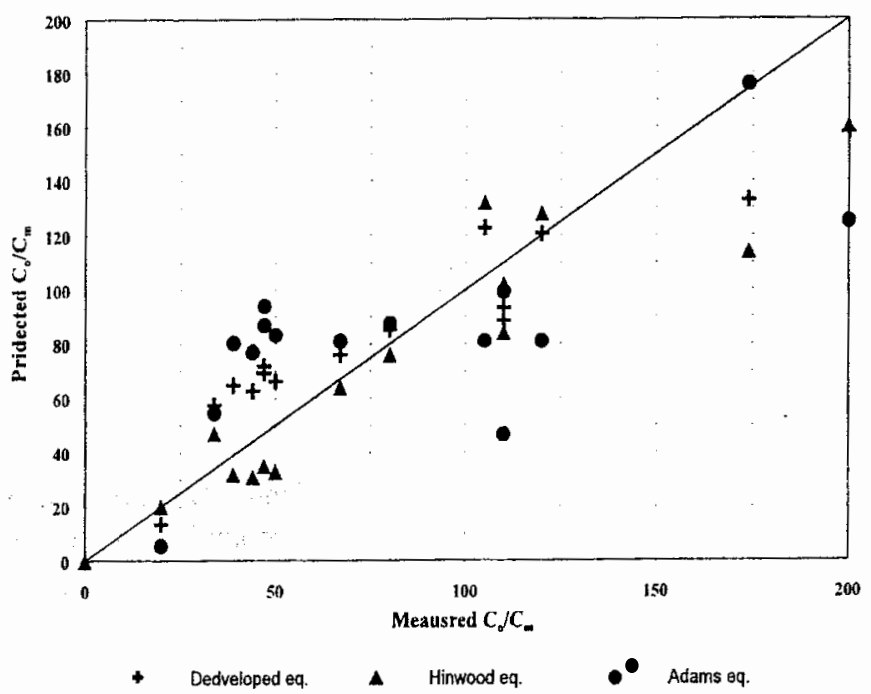

Figure (10) Comparison of Measured and Predicted $C_{v} / C_{m}$ for Multi-port Diffuser in an estuarine channel 
التصريف الحراري من مشتت متعدد الفتحات إلى الأنهار ذات المياه

\section{الضحلة}

أ.م.د/ قلسم صلاح عبد الوملب الألفي

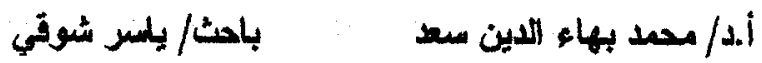

أ.م. أبحمد معد فؤاد صبيع

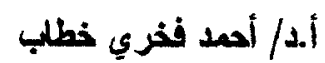

\section{النلاصة}

فى هذا البحث تم بر اسة ظاهرة التصريف الحرارى في الأنـــهار ذات الميــاه

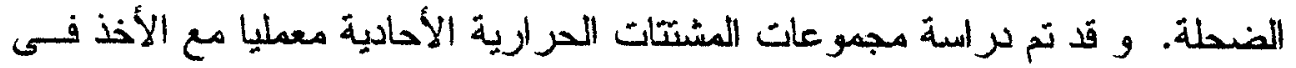

الاعتبار الخصائص المختلفة لمنشأ التصريف الحرارى و مختلف المتغيرات الخاصسة

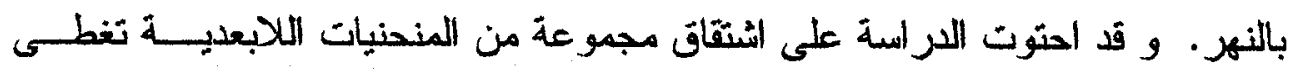

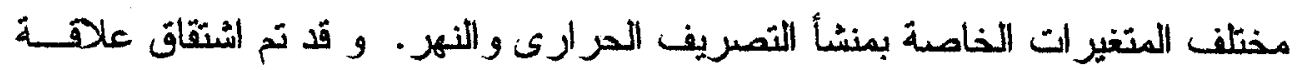
عامة تقريبية تستخدم فى تصميم منشأ التصريف الحرارى لتصريف المــاء السبـاخن

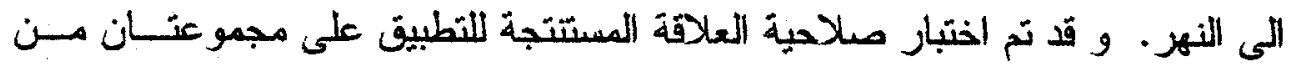
القياسات الحقلية لمنشآت في الطبيعة ، حيث تمثل المجموعتان فيسـم نسـبـة التركسيز

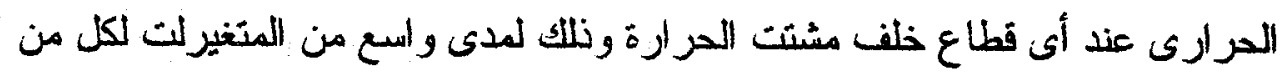

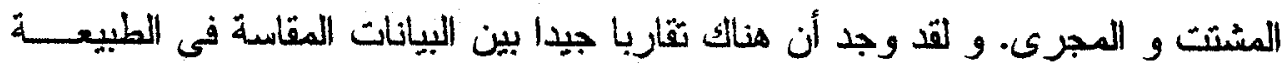

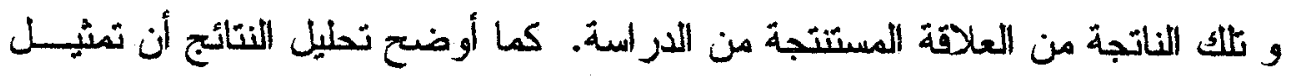
البيانات المقاسة و تلك المستنتجة فى شكل علاقات يعطى ذات الشكل و ذات الاتجـــــاه

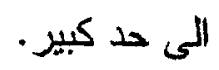

